\title{
MOLECULAR GENETIC ANALYSIS IN FAMILIAL ISOLATED PITUITARY ADENOMA PATIENTS
}

Tatiana Tarasova, Elizaveta Mamedova, Ekaterina Pigarova, Elena Przhiyalkovskaya, Larisa Dzeranova, Ludmila Rozhinskaya, Anatoly Tulpakov, Ivan Dedov Endocrinology Research Centre, Moscow, Russian Federation

\section{Introduction}

FIPA - is a syndrome which includes pituitary adenomas with any kind of secretion in two or more members in a family in the absence of MEN or Carney complex; it also includes isolated family somatotropin syndrome (IFS).

\section{Aim}

Molecular genetic study of a gene panel in FIPA patient.

\section{Materials and methods}

Study included 1 family (2 men, 24 and 58 years) with pituitary adenomas with homogeneous secretion type somatotropinomas.

Brain MRI: macroadenomas (maximum size of $39 \mathrm{~mm}$ ). One patient after combination therapy (somatostatin analogs in the maximum dose and primary surgery, without radiological therapy), another patient without any treatment at the time of the study. There were no normalization of $\mathrm{GH}$ and IGF.
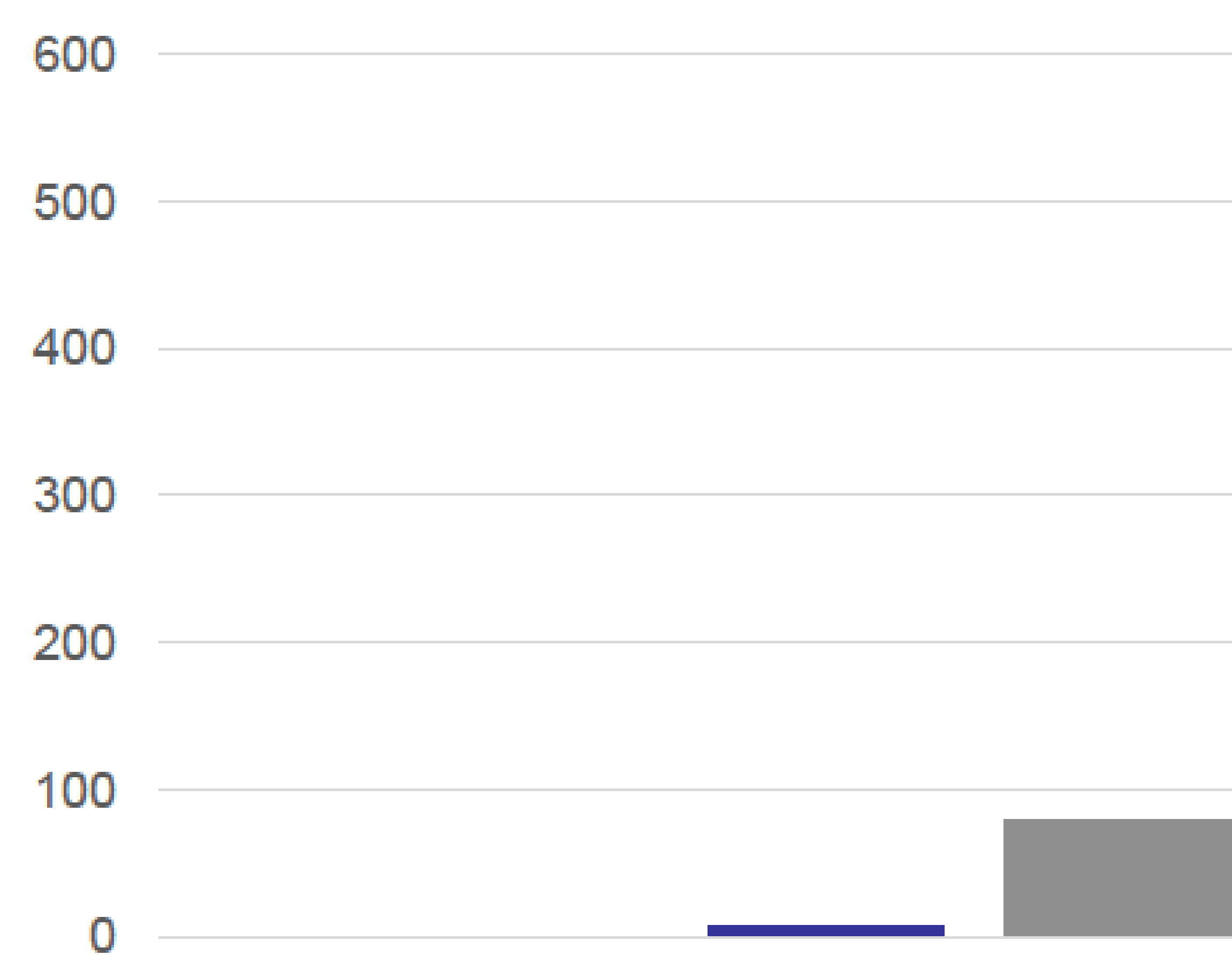

$\mathrm{GH}, \mathrm{ng} / \mathrm{ml}$

lowel limit of normal
Genomic DNA from a blood samples of patients underwent high-throughput sequencing on the lon Torrent Personal Genome Machine (Life Technologies) using a custom-designed AmpliSeq panel for the sequencing of a panel of genes (MEN1, CDKN1B, PRKAR1A, GNAS, AIP, SDHA, SDHB, SDHC, SDHD, PRKCA, CDKN2C, CDKN2A, POU1F1, PTTG2).

\section{Results}

Direct sequencing revealed mutation in exon 6 of the gene AIP p.R271W, which was not previously described in studies.

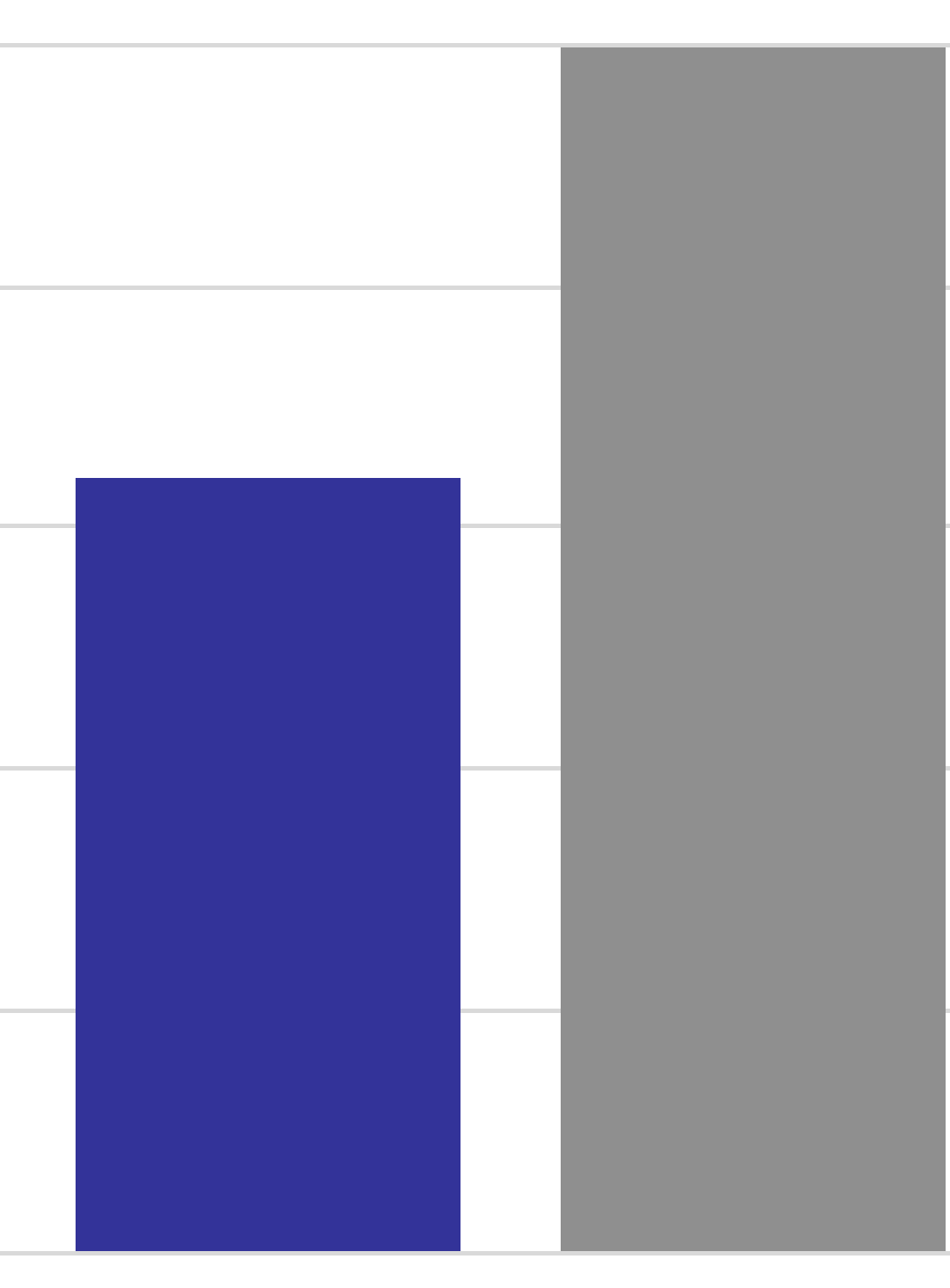

IGF, ng/ml

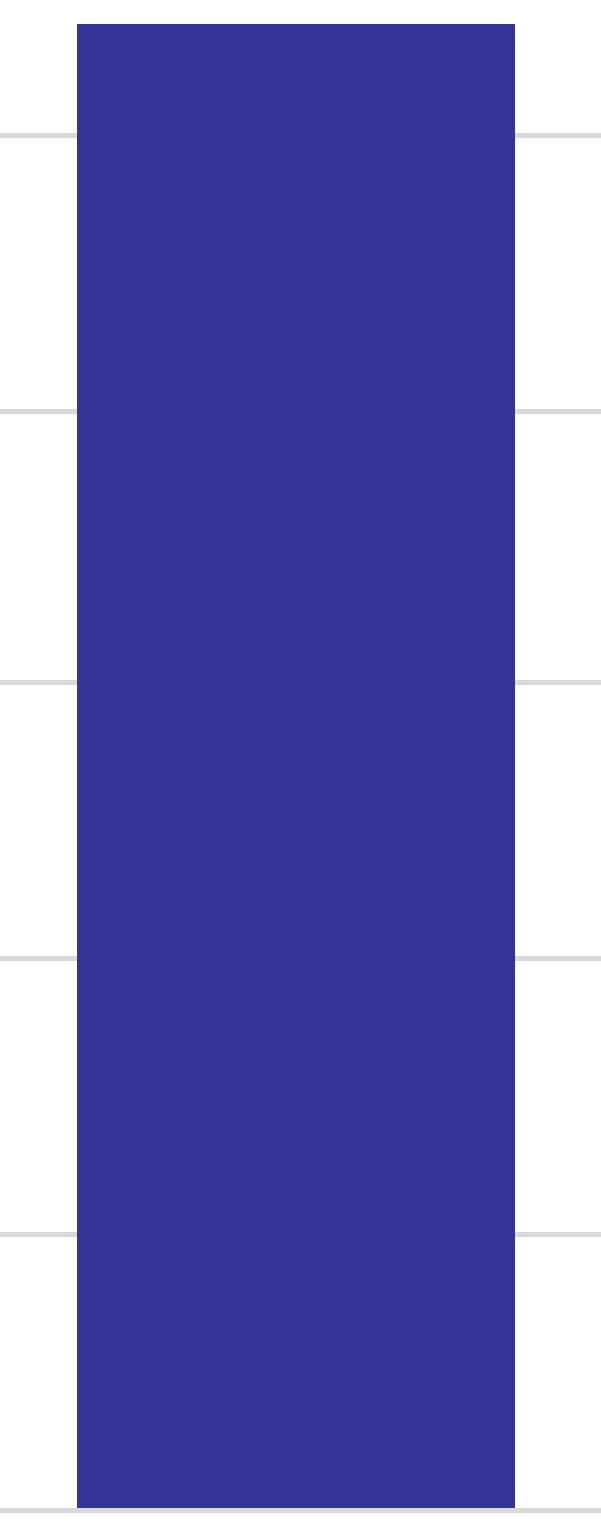

Prolactin, $\mathrm{mU} / \mathrm{l}$

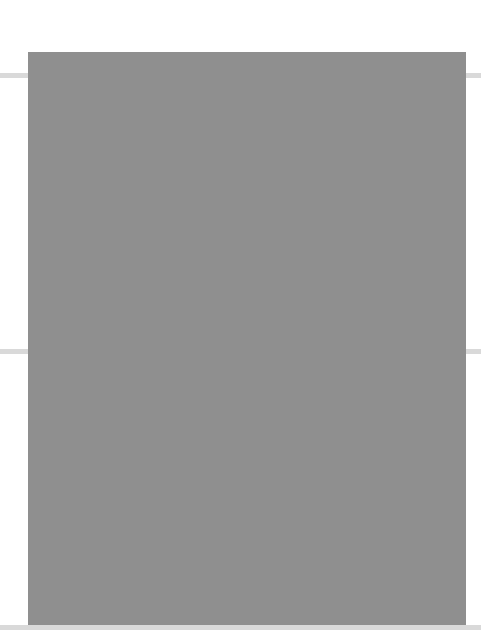

median 